\title{
ANÁLISE DO USO E OCUPAÇÃO DAS TERRAS EM PEQUENAS BACIAS HIDROGRÁFICAS DO SEMIÁRIDO ALAGOANO: RIACHOS DA TORTA E DO MEL NO ALTO CURSO DO RIO TRAIPÚ
}

\author{
Denize dos Santos ${ }^{(a)}$, Cícero Bezerra da Silva ${ }^{(b)}$, Jailma Ferro Cabral ${ }^{(\mathrm{c})}$ \\ ${ }^{(a)}$ Doutorana do Programa de Pós-Graduação em Geografia - PPGEO/UFS; Departamento de geografia, \\ Universidade Estadual de Alagoas- UNEL denize_ambiente@ hotmail.com

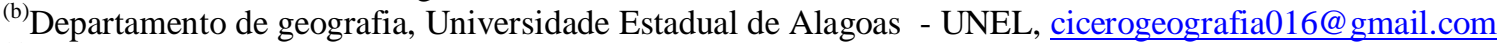 \\ ${ }^{(c)}$ Departamento de geografia, Universidade Estadual de Alagoas - UNEAL, jailmaferrocabral@ gmail.com
}

\section{EIXO 1: BACIAS HIDROROGRÁFICAS E RECCURSOS HÍDRICOS: ANÁLISE, PLANEJAMENTO E GESTÃO}

\begin{abstract}
Resumo
A análise de bacias hidrográficas é fundamental na compreensão da dinâmica das águas, principalmente em áreas semiáridas onde a questão hídrica encontra-se no limiar de escassez qualitativa e quantitativa mediante o mau uso que se faz dos elementos naturais. Assim, esse trabalho objetiva a realização do mapeamento de uso e ocupação das terras da sub-bacia dos riachos da Torta e do Mel, contribuintes da rede de drenagem do rio Traipú, no sertão alagoano. A metodologia empregada no desenvolvimento do trabalho refere-se a análise bibliográfica e ao uso de técnicas de geoprocessamento em conjunto com os trabalhos de campo. Os resultados obtidos mostram que o uso das terras ao longo da sub-bacia são caracterizados em três classes principais: a pastagem, a caatinga semi densa e a caatinga densa. Além disso, foi possível identificar muitas manchas de solos expostos resultantes dos processos de degradação e também da fragilidade natural da sub-bacia.
\end{abstract}

Palavras chave: Bacia Hidrográfica, Uso da Terra, Semiaridez.

\section{Introdução}

As bacias hidrográficas são importantes unidades de planejamento e estudo, levando em consideração seu caráter sistêmico e integrado que permite reconhecer e avaliar os diferentes componentes da paisagem sejamestes naturais ou antrópicos, resultantes da ação humana. Essa visão integrada proposta por Guerra e Cunha (2012) permite uma abordagem conjunta do comportamento desses sistemas naturais, auxiliando seu entendimento e a posterior tomada de decisões.

Como unidade física, delimitada naturalmente pelos divisores de água que são reconhecidos como a parte mais elevada do terreno, as bacias hidrográficas de qualquer hierarquia podem ser compreendidas como a área da superfície da terra drenada por um rio principal e seus tributários (CUNHA e GUERRA, 2012; BOTELHO e SILVA, 2012; COELHO NETTO, 2015 et al). Essas bacias, "representam a área de captação natural da água das precipitações que faz convergir o escoamento para um único ponto de saída, o exutório" (NOVO, 2008, p. 220). 
Os agentes atuantes no interior de uma bacia hidrográfica, incluindo ação do homem interferem diretamente na sua forma física, no arranjo dos canais e nos caminhos tomados pela água nos processos de escoamento. Essas ações, não levam em consideração a fragilidade e as condições naturais dos ambientes fluviais e sua dinâmica própria, resultando assim na falência da natureza e em sérias consequências também para o homem como parte integrante do sistema. Como sistema integrador, as bacias hidrográficas ou de drenagem vem ocupando ao longo dos anos lugar de destaque nos estudos de planejamento e análise ambiental, incorporando o elemento humano (ações) e elementos naturais (solo, água, rocha, vegetação).

Sobre o levantamento de uso e ocupação da terra é possível considerar que tais informações ajudam no entendimento da organização socioespacial do território, dando ênfase aos tipos de culturas produzidas em uma região, os hábitos da população e os recursos por ela utilizados. Essas análises permitem ainda a espacialização da forma de organização do território e dos usos a ele atribuindo.

As informações de uso e ocupação da terra de uma determinada área podem ser mais bem analisadas a partir do mapeamento de uso e ocupação da terra, que representa a possibilidade de espacialização das atividades humanas em conjunto com os elementos naturais.

Nessa perspectiva, esse estudo tem por objetivo a realização do mapeamento de uso e ocupação das terras da sub-bacia hidrográfica dos riachos da Torta e do Mel, contribuintes do sistema de drenagem do rio Traipú (alto curso), na região semiárida do estado de Alagoas. A partir dessa caracterização tornarse-á possível a identificação dos principais fatores de degradação que atingem a sub-bacia, apontando assim suas causas e as relações existentes entre as atividades antrópicas desenvolvidas no recorte espacial de análise e os processos de degradação da natureza.

\section{Os riachos da Torta e do Mel:uso e ocupação das terras}

\section{Material e Métodos}

A sub-bacia hidrográfica dos riachos da Torta e do Mel drena uma área de aproximadamente 106 $\mathrm{km}^{2}$, inserida nos municípios de Minador do Negrão e Cacimbinhas. Os divisores topográficos da subbacia (área Norte), correspondem ao conjunto de serras que fazem a divisa dos Estados de Pernambuco e Alagoas sob influência direta das encostas Sudoeste do Planalto da Borborema.

Assim como toda a rede de drenagem do rio Traipú, assub-bacias dos riachos da Torta e do Mel estão inseridas na depressão sertaneja do São Francisco, apresentando valores altimétricos inferiores a 230 
metros. Essa característica é resultante de um relevo que apresenta superfícies aplainadas que contrastam com um pequeno domínio de morros e serras baixas intensamente degradadas por fatores hidrogeomorfológicos e antrópicos. A sub-bacia está inserida em uma área sujeita à ocorrência de processos de desertificação (IMA, 2010), que podem ser ocasionados pelas condições de semiaridez associadas ao mau uso do solo e dos demais recursos naturais.

A sub-bacia em estudo apresenta uma rede de drenagem pouco extensa, onde o canal principal mede aproximadamente 30 metros de comprimento com drenagem intermitente, estando assim diretamente relacionado às precipitações periódicas. A cobertura vegetal original corresponde a Caatinga, bioma endêmico do Nordeste brasileiro e da porção Norte do Estado de Minas Gerais (NASCIMENTO, 2006). Por estar inserida em uma área tipicamente rural, a atividade que mais se destaca na bacia é a agropecuária, sendo também a mais danosa a esse sistema fluvial.

No desenvolvimento da pesquisa foram realizadas leituras e discussões de cunho teórico conceitual referentes às formas de mapeamento e análises de bacias hidrográficas. Assim, destacam-se os estudos desenvolvidos por: Christofoletti (1980), Novo (2008) e Guerra e Cunha (2012). Por se tratar da análise de um sistema natural inserido no semiárido buscou-se também a apropriação das discussões desenvolvidas por Nascimento (2006), Rocha $(2008,2013)$ e Cavalcante (2014). A pesquisa está pautada na abordagem geossistêmica que engloba tanto elementos naturais quanto as ações do homem enquanto sujeito modelador e transformador da paisagem.

Na delimitação da sub-bacia dos riachos da Torta e do Mel fez-se necessária a aquisição da carta topográfica da SUDENE folha: SC - 24 -X Palmeira dos Índios escala 1: 100 000, digitalizada e georreferenciadapelo Instituto de Meio Ambiente de Alagoas - IMA (2010). Essa delimitação foi realizada com base no perfil altimétrico a partir da aquisição dos dados do projeto Topodata/SRTM (Shutt Radar TopographicMission) atualmente disponibilizados no site da Empresa Brasileira de Pesquisa Agropecuária - EMBRAPA e do Instituto Nacional de Pesquisa Espacial - INPE.

O mapeamento de uso e ocupação da terra foi realizado a partir dos dados do Instituto de Meio Ambiente de Alagoas - IMA (2010), atualizado a parir de análises desenvolvidas no software Google Earth com imagens atualizadas no ano de 2016. Além disso, a construção do mapa temático de uso e ocupação da terra foi realizado a partir dos dados e observações realizadas no trabalho de campo, que por sua vez objetivou a análise sistêmica dos elementos naturais (vegetação, hidrografia, relevo) e humanos (atividade econômica, forma de uso da terra, impactos, etc.). 


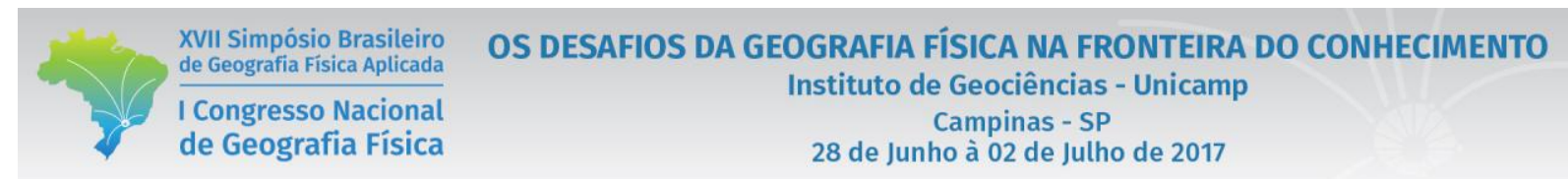

No trabalho de campo foram usadas cadernetas de campo (ou diário de campo), essencial à anotação e relatos das experiências vivenciadas in loco, câmeras fotográficas e um GPS (Sistema de Posicionamento global) modelo Garmin (DAKOTA 10-20).

Sobre o desenvolvimento e a importância dos trabalhos de campo é possível considerar que os mesmos "constituem uma metodologia que engloba a observação, a análise e a interpretação dos fenômenos no local e nas condições onde eles ocorrem naturalmente” (NEVES, 2010, p. 15).

O processamento dos dados, a montagem do banco de dados coletado em campo e a confecção dos mapas foram realizados como software de código aberto QGIS (2.8.0). A análise da produção cartográfica bem como das questões teóricas referentes à linha de pesquisa foram realizadas no Laboratório de Estudos Ambientais e Cartográficos (LEAC), no campus III da Universidade Estadual de Alagoas (UNEAL).

\section{Uso da Terra nasSub-bacias dos Riachos da Torta e do Mel}

A partir do mapeamento de uso e ocupação da terra em conjunto com trabalho de campo foi possível identificar que assub-bacias dos riachos da Torta e do Mel apresentam características tipicamente rurais e a atividade econômica dominante é a pecuária extensiva.

Essa característica pode ser justificada pela existência de várias fazendas na região, representadas em sua maioria por um sistema de produção de técnicas ainda rudimentares, com trabalho desenvolvido de forma intuitiva que não leva em consideração as limitações naturais do terreno. Sobre as fazendas é possível considerar que as mesmas se formaram a partir do processo de interiorização do gado no Nordeste brasileiro, se afastando da zona canavieira. (MOREIRA, 2015).

O levantamento sobre o uso e a cobertura da terra comporta análises e mapeamentos e é de grande utilidade para o conhecimento atualizado das formas de uso e ocupação do espaço, constituindo importante ferramenta de planejamento e de orientação à tomada de decisões. Ao retratar as formas e a dinâmica de ocupação da terra, esses estudos também representam instrumento valioso para a construção de indicadores ambientais e para a avaliação da capacidade de suporte ambiental, diante dos diferentes manejos empregados na produção, contribuindo assim para a identificação de alternativas promotoras da sustentabilidade do desenvolvimento. (IBGE, 2006, p. 20).

A observação do mapa de uso e ocupação da terra (mapa 1) permite identificar a distribuição dos fenômenos ocorrentes na sub-bacia de forma integrada, envolvendo o homem e os elementos naturais. Essa análise evidencia como está se dando ao longo do tempo o processo de ocupação e também de degradação do recorte de análise. 


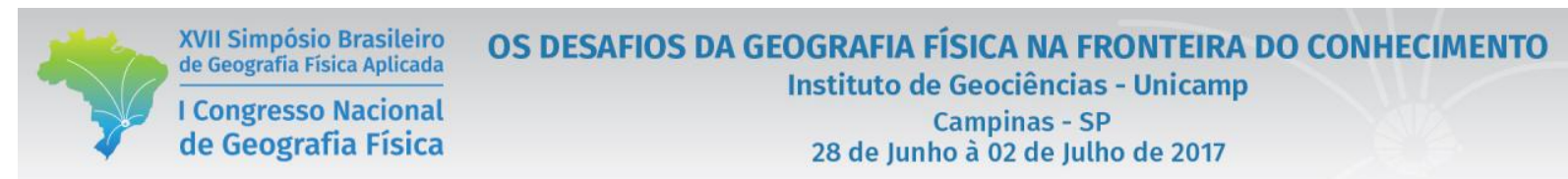

Conforme apresentado, formam identificados na sub-bacia três domínios de uso e ocupação: pastagem, Caatinga densa e caatinga semidensa. Embora não representados no mapeamento em função da escala de análise, existem alguns pontos ao longo da sub-bacia onde se pratica a agricultura temporária de subsistência, desenvolvida nas proximidades dos canais de drenagem e nas áreas mais úmidas da subbacia.

Dentre as culturas temporárias desenvolvidas na sub-bacia destacam-se o milho, a mandioca e o feijão, que ocorrem de forma pontual. A palma, muito usada na alimentação animal em períodos de longa estiagem também é cultivada em áreas levemente onduladas. Segundo o Manual Técnico de Uso da Terra do IBGE as lavouras temporárias ou de subsistência devem ser compreendidas como:

Sistemas produtivos que constituem a base alimentar e também fonte de renda básica para pequenos e médios produtores. Os cultivos variam de acordo com as características regionais em função de suas potencialidades edafoclimáticas e socioculturais. Na maior parte dos estados elas estão centradas nos cultivos de mandioca, milho, feijão e tubérculos. Via de regra, correspondem a estabelecimentos de até 10 há, podendo eventualmente chegar a estabelecimentos de até 50 ha, empregam tecnologia rudimentar e mão-de-obra basicamente familiar (IBGE, 2006, p. 27).

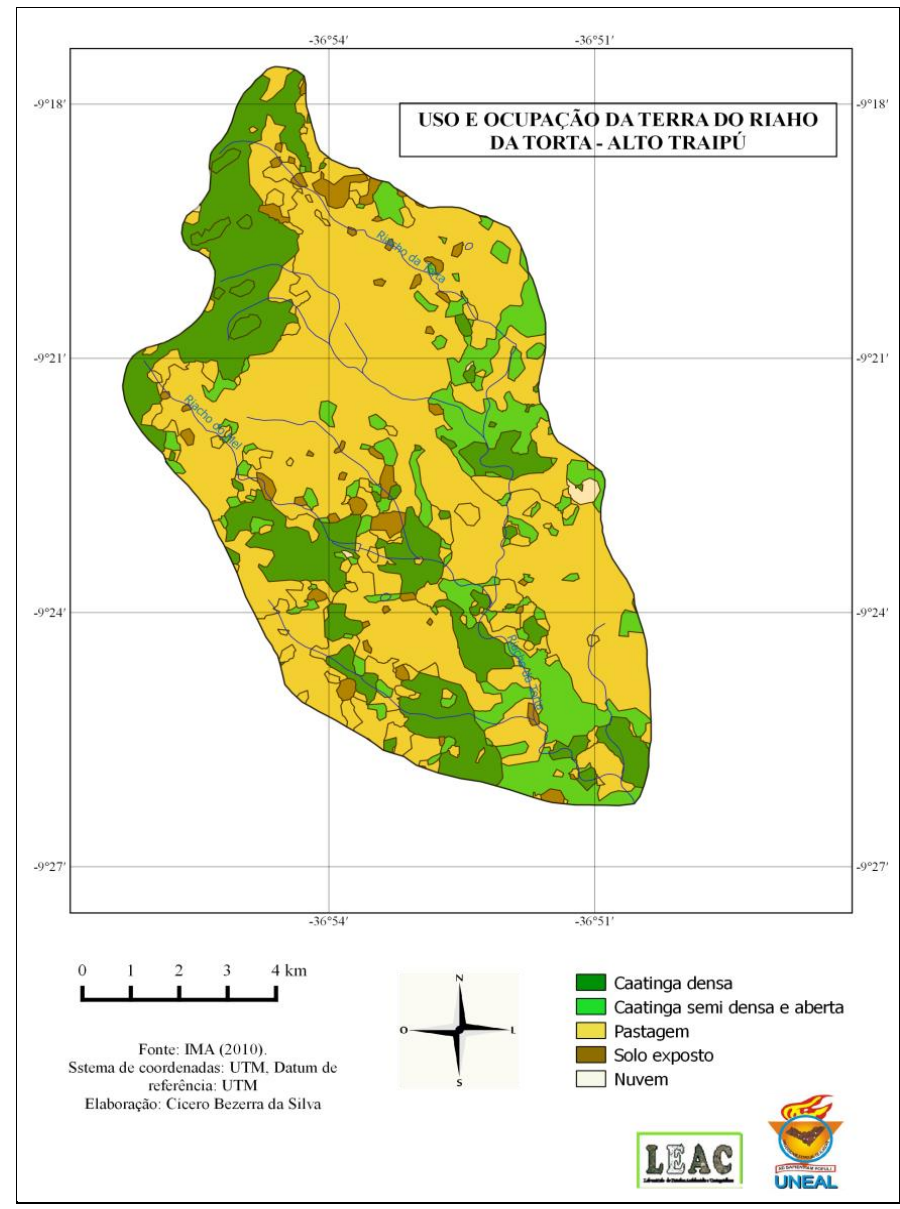

Mapa 1 - Uso e ocupação da terra da sub-bacia dos riachos da Torta e do Mel 
XVII Simpósio Brasileiro de Geografia Fisica Aplicada

I Congresso Nacional de Geografia Física
OS DESAFIOS DA GEOGRAFIA FÍSICA NA FRONTEIRA DO CONHECIMENTO

Instituto de Geociências - Unicamp

Campinas - SP

28 de Junho à 02 de Julho de 2017

Fonte: IMA (2010), e trabalho de campo (2016)

Essas características estabelecidas pelo IBGE são perceptíveis ao longo da sub-bacia, onde as condições naturais do clima e do próprio solo permitem apenas o desenvolvimento de culturas temporárias e de subsistência. Essas propriedades, caracterizadas por pequenas parcelas de terra são trabalhadas de forma intuitiva e não levam em consideração as condições naturais da região, o que intensifica evidentemente a degradação do ambiente. O domínio representado pela Caatinga densa é predominante nos divisores de água da sub-bacia e na proximidade da confluência dos canais de drenagem. A Caatinga semidensa corresponde às áreas de maior antropização, de expansão da pecuária e das atividades de subsistência.

\section{Identificação de Processos Degradacionaisna Paisagem dos Riachos da Torta e do Mel}

A identificação e análise dos processos de degradação da sub-bacia foram realizadas levando em consideração as formas de uso da terra e as condições naturais do ambiente, conforme a proposta de Cunha e Guerra que apontam para a necessidade de que "ao se caracterizar processos físicos, como a degradação ambiental, deve-se levar em consideração critérios sociais que relacionam a terra com seu uso" (2012, p.342). Assim, a partir da espacialização de uso e ocupação da terra da sub-bacia foi possível verificar variadas parcelas de solo exposto (mapa 3) que chamam atenção pela proporcionalidade em relação ao tamanho da sub-bacia.

A ocorrência do problema evidenciado no mapeamento (mapa 3 representado acima) é resultado da intensa exploração agrícola sem manejo e da substituição cada vez mais intensa da vegetação natural pela pastagem. Esses solos expostos favorecem um acelerado processo de erosão, principalmente em áreas de encostas e vertentes, descaracterizando os canais fluviais e empobrecendo os solos. Considera-se também que,

A erosão dos solos tem causas relacionadas à própria natureza, como a quantidade e distribuição das chuvas, a declividade, o comprimento e forma das encostas, as propriedades químicas e físicas dos solos, o tipo de cobertura vegetal, e também à ação do homem, como o uso e manejo da terra que, na maioria das vezes, tende a acelerar os processos erosivos [...]. As principais causas para a ocorrência desses processos de erosão acelerada são o desmatamento e o posterior uso do solo para a agricultura e pecuária. (GUERRA; MENDONÇA, 2012, p. 225). 


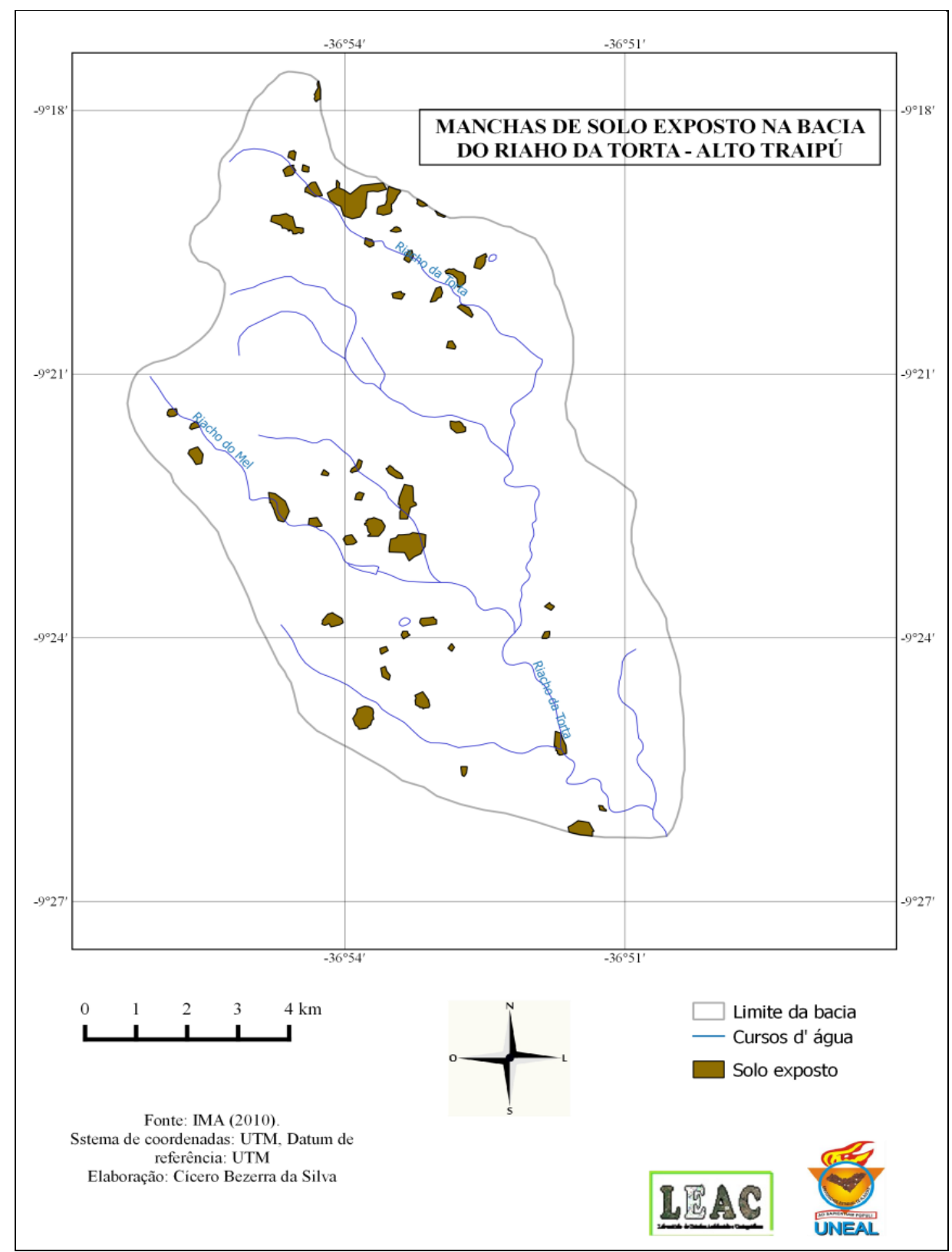

Mapa 2 - Manchas de solo exposto na sub-bacia dos riachos da Torta e do Mel Fonte: IMA (2010); Google Earth (2016).

O uso desordenado e inconsequente da terra da sub-bacia está ocasionando a degradação tanto das estruturas dos canais fluviais (calha dos riachos), quanto das terras da bacia. Esses problemas podem, em um curto período causar perdas econômicas, havendo assim um verdadeiro desequilíbrio socioambiental. Os processos de degradação do solo, associada à escassez hídrica e àpouca cobertura vegetal podem contribuir para o desenvolvimento de focos de desertificação. 


\section{Conclusão}

No que se refere à sub-bacia dos riachos da Torta e do Mel é possível considerar que os usos atribuídos a essa unidade ambiental está diretamente relacionado às atividades agrárias, que por vez formam boa parte da paisagem da bacia, contrastando com a Caatinga intensamente degradada. É possível considerar a importância dessa bacia na manutenção das atividades agrícolas e domésticas em períodos de estiagem, que mesmo com regime fluvial pobre e sem escoamento superficial possibilita aquisição de água, seja em pequenos barramentos ou em poços escavados pela população local no leito dos rios/riachos.

Os processos de degradação desse sistema fluvial estão associados diretamente ao mau uso dos recursos naturais, mas deve-se levar em conta também a fragilidade imposta pelas condições naturais da região, principalmente aquelas relacionadas ao clima. A escassez hídrica associada à baixa cobertura vegetal está ocasionando sérios danos ao solo, deixando-o exposto e susceptível a degradação.

\section{Referências}

BOTELHO, Rosangela Garrido Machado. Planejamento Ambiental em Microbacia Hidrográfica. In: GUERRA, Antonio José Teixeira; SILVA, Antonio Soares; (org.). Erosão e Conservação dos Solos: conceitos, temas e aplicações. 7 ed. Rio de Janeiro: Bertrand Brasil, 2012.

CHRISTOFOLETTI, Antonio. Geomorfologia. 2 ed. São Paulo: Edgard Blucher, 1980.

COELHO NETTO. Hidrologia de Encostas na Interface Com a Geomorfologia. In: CUNHA, Sandra Baptista da; GUERRA, Antonio José Teixeira (org.). Geomorfologia: exercícios, temas e aplicações. Rio de Janeiro: Bertrand Brasil, 1996.

CUNHA, Sandra Baptista da; GUERRA, Antonio José Teixeira (orgs.). Degradação Ambiental. In: Geomorfologia e Meio Ambiente. 11 ed. Rio de Janeiro: Bertrand Brasil, 2012.

; Geomorfologia Fluvial. In: GUERRA, Antonio José Teixeira; CUNHA, Sandra Baptista da (org.). Geomorfologia: uma atualização de bases e conceitos. 13 ed. Rio de Janeiro: Bertrand Brasil, 2015.

MOREIRA, Ruy. Sociedade e Espaço Geográfico no Brasil. São Paulo: Contexto, 2015.

NEVES, Karina Fernandes TravagimViturino. Os trabalhos de campo no ensino de geografia: reflexões sobre a prática docente na educação básica. Ilhéus - BA: Editus, 2010.

NOVO, Evlyn Márcia L. de. Ambientes Fluviais. In: FLORENZANO, Teresa Gallotti (org.). Geomorfologia: conceitos e tecnologias atuais. São Paulo: Oficina de Textos: 2008.

INSTITUTO BRASILEIRO DE GEOGRAFIA E ESTATISTICA - IBGE. Manual Técnico em Geociências. 2 ed. Rio de Janeiro: IBGE, 2007.

INSTITUTO DE MEIO AMBIENTE DE ALAGOAS - IMA. Dawnlod de dados vetoriais. Disponível em: < http://www.ima.al.com.br/dwloddedadosvetoriais >. Acesso em: Ago. de 2015. 